\title{
El expediente de la sublevación de los pampas en Santa Ana (1888, Misiones, Argentina)
}

The record of the Pampas' revolt in Santa Ana (1888, Misiones, Argentina)

\section{Diana Lenton}

\section{OpenEdition}

Journals

\section{Electronic version}

URL: http://journals.openedition.org/corpusarchivos/1873

DOI: 10.4000/corpusarchivos.1873

ISSN: $1853-8037$

\section{Publisher}

Diego Escolar

\section{Electronic reference}

Diana Lenton, «El expediente de la sublevación de los pampas en Santa Ana (1888, Misiones, Argentina) », Corpus [En línea], Vol. 7, No 1 | 2017, Publicado el 04 julio 2017, consultado el 20 abril 2019. URL : http://journals.openedition.org/corpusarchivos/1873 ; DOI : 10.4000/ corpusarchivos.1873

This text was automatically generated on 20 April 2019.

Licencia Creative Commons: Atribución-NoComercial 2.5 Argentina (CC BY-NC 2.5 AR) 


\section{El expediente de la sublevación de los pampas en Santa Ana ${ }^{1}$ (1888, Misiones, Argentina)}

The record of the Pampas' revolt in Santa Ana (1888, Misiones, Argentina)

\section{Diana Lenton}

\section{Agradecimientos}

A Julio Cantero y Ana Zanotti.

Al personal del Archivo de la Gobernación en Posadas.

Al personal de la Biblioteca Popular de Santa Ana.

\section{Presentación}

1 El expediente del "Sumario levantado con motivo de la sublevación i fuga de los indios pampas que trabajaban en el establecimiento del Señor General Don Rudecindo Roca" por el juez de paz de Santa Ana, Misiones, entre el 24 y el 30 de junio de 1888, se encuentra en el Archivo General de la Gobernación de Posadas, y fue catalogado en algún momento como "Legajo 174".

El original se perdió en ocasión del incendio que afectó a los archivos del Poder Judicial de la provincia, en 2010. Afortunadamente un historiador y periodista misionero, Julio Cantero, había realizado una copia facsimilar del mismo con anterioridad, que donó al archivo tras el siniestro; copia de cuya existencia me informó, por lo cual mi reconocimiento es doble.

3 En febrero de 2012 visité la localidad de Santa Ana, donde relevé los documentos existentes en la Biblioteca Pública y recorrí parte de las antiguas locaciones del Ingenio San Juan, hoy cubiertas por la selva. En Posadas revisé las colecciones del diario El Territorio; todo ello con el fin de profundizar en la contextualización de los hechos que 
analizaremos. No obstante, es la copia del expediente del proceso abierto por el juez de paz de Santa Ana en 1888, y que fotografié en el Archivo Judicial en Posadas, el material que me interesa presentar en particular, dada su extraordinaria riqueza.

4 El expediente se abre el 24 de junio de 1888, con el "Auto cabeza de proceso" por el cual el juez Mujica declara haber tomado conocimiento de los hechos a partir de la denuncia realizada por Jordán Hummel, mayordomo del establecimiento, y finaliza 50 fojas después, con el pedido al Estado paraguayo de la captura y extradición de los jefes de la rebelión: Yancamil y Melideo. Contiene las declaraciones de diecisiete testigos presenciales de la sublevación, quienes responden a las preguntas del Juez desde su propia perspectiva.

5 A continuación, contextualizaré y transcribiré el contenido completo del documento, para facilitar su lectura, además de adjuntar la copia facsimilar.

\section{Notas sobre las políticas de repartimiento de prisioneros indígenas a fines del siglo XIX}

6 El 24 de agosto de 1885 el ministro de Guerra y Marina, Francisco Ortiz, inquirió ante la Cámara de Diputados de la Nación "qué se va a hacer con estas tribus de indios, que vienen á someterse voluntariamente" (Lenton 2005). Efectivamente, las incursiones militares en los últimos territorios autónomos indígenas en la actual geografía argentina tuvieron como correlato el sometimiento de miles de sus pobladores a diferentes prácticas de privación de la libertad, trabajo forzado, incorporación forzada al ejército vencedor, separación de sus integrantes, apropiación y tráfico de niños y adultos, exposición al hambre, la enfermedad y el deterioro físico y mental, e imposición compulsiva de las marcas culturales del sector hegemónico. Esta política, presentada ante la opinión pública como la forma más "racional" de atender el "saldo humano" de la Conquista del Desierto, contribuyó a crear lo que en palabras de Mases (2002) constituyó la "primera cuestión social", antes de la cuestión inmigratoria, conformando uno de los focos más intensos del debate público en el período de entre siglos.

7 La respuesta político-militar a la pregunta de Ortiz fue dirigida por las necesidades de las nuevas agroindustrias (Pucci 1986, 1989; Iñigo Carrera 1988; Campi 1992; Rofman 1999), que, combinadas con los requerimientos geopolíticos de los nuevos territorios nacionales, fueron presentadas como destinos positivos para las poblaciones que debían ser aún civilizadas mediante el trabajo (Escolar y Saldi 2016; Delrio 2005). En particular, la industria azucarera en nuestro país que en su momento de esplendor se caracterizó por el reclutamiento de mano de obra prisionera, distribuida directamente desde la "frontera con el indio" o desde los campos de concentración de isla Martín García y otros, para su utilización servil (Rosenzvaig 1986; Mases 1987; Conti et al. 1988; Teruel 1991; Nagy y Papazian 2011; Pérez 2007, 2016). ${ }^{2}$

Graciana Pérez Zavala (2012) reconstruye minuciosamente el desarrollo de las expediciones militares que asolaron las tolderías ranquelinas entre 1875 y 1880, durante las cuales la caza de prisioneros indígenas llegó a proporciones inauditas. Cientos de prisioneros y familias quedaron en las ciudades de Sarmiento y Villa Mercedes. La autora también verifica los itinerarios diferenciales de la gente indígena en función de la autoridad militar que los hubiera reducido: mientras que los retenidos por el coronel Rudecindo Roca ${ }^{3}$ en 1878 fueron enviados directamente desde Río Cuarto a Tucumán, los 
que fueron apresados en 1878 por el coronel Eduardo Racedo habrían sido trasladados desde Sarmiento a Río Cuarto y de allí a la isla Martín García. En cambio, los aprisionados en 1879 habrían permanecido en la región. ${ }^{4}$ Esto demuestra la discrecionalidad con que se tomaron decisiones sobre los cuerpos indígenas, dependiendo no solo del contexto y las presiones más amplias sino también de la red de relaciones y los intereses de cada oficial.

En este contexto se produjo la acción militar a cargo de Rudecindo Roca que perduró en la historia como la "Masacre de Pozo del Cuadril" y que desencadenó en su momento graves críticas como las del diario La Nación, en las que se apeló a la calificación de crimen de lesa humanidad. ${ }^{5}$ En octubre de 1878, según reconstruye José Depetris (2002), un contingente de "guerreros ranquelinos" se dirigió a Villa Mercedes de San Luis a cobrar las raciones estipuladas en el pacto firmado meses antes entre el gobierno nacional y los caciques Epugner Rosas y Manuel Baigorria. Uno de los guerreros al frente de esta comisión era José Gregorio Yancamil. ${ }^{6}$ El resultado de lo que debía ser un intercambio pacífico fue el ataque sorpresivo efectuado por las tropas nacionales, el fusilamiento masivo de los varones capturados y el envío de las familias, en diciembre de ese año, a la zafra tucumana. ${ }^{7}$ Yancamil quedó prisionero y reponiéndose de sus heridas, perdiendo a su mujer e hijas que, como el resto de los ranqueles enviados a Tucumán, nunca regresaron (Depetris 2002).

Sin embargo, volvemos a encontrar al cacique José Gregorio Yancamil el 19 de agosto de 1882, cerca de Cochicó, liderando la que pasó a la historia pampeana como la última batalla militar ranquelina. Tras su derrota, el cacique y los demás prisioneros ranquelinos fueron trasladados a la isla Martín García (Pérez Zavala 2012).

\section{Los pampas en Santa Ana}

11 En 1884, el primer gobernador del Territorio Nacional de Misiones, Rudecindo Roca, veterano de la Campaña al Desierto -y responsable en 1878 de la mencionada "matanza del Cuadril"-, instaló el ingenio azucarero San Juan de su propiedad cerca de la actual localidad de Santa Ana. El ingenio, muy extenso, contaba con gran variedad de establecimientos destinados a su autoabastecimiento: panadería, ladrillera, herrerías, etc., ferrocarril interno y un par de barcos a vapor que cumplían el trayecto Santa AnaPosadas (Bourgoing 1894). Una de sus características, muy comentada por los científicos viajeros de la época (Holmberg 1887; Bourgoing 1894; Daireaux 1888, cit. en Gutiérrez et al. 2014; Ambrosetti 2008 [1893, 1894, 1896]), era la conformación de su mano de obra, casi en su totalidad, por prisioneros indígenas pampeanos y chaqueños. Como ocurriera con muchos ingenios tucumanos, la provisión de mano de obra esclava fue subsidiada por el Estado nacional que se hizo cargo de su captura, traslado y disciplinamiento. ${ }^{8}$

La caña se recoge como hemos visto en Tucumán, empleándose para ello indios procedentes de las pampas después de la sumisión de esta región en 1880. Levantan ahí sus tiendas como lo hacían en el desierto, sin que el contacto de la civilización haya modificado ni sus costumbres ni su manera de construir; solo se han expatriado bajo el sol más ardiente de las Misiones continuando viviendo como en el llano frio del sur. Los Pampas se encuentran mezclados con algunos indios tobas llevados del Chaco (...) (Daireaux 1888, cit. en Gutiérrez et al. 2014).

12 En 1886 el Gobernador solicitó, y obtuvo, que se le permitiera acceder a una cantidad ilimitada de familias "pampas" para el trabajo en sus propiedades. Una nota fechada el 4 
de febrero de 1886 por el Estado Mayor de la Armada le comunicó al comandante de la isla Martín García: la persecución que el infrascripto les hizo en la margen del río en la costa argentina. Buscando detenerlos, hicieron resistencia y trataron de asaltarnos (...) No tuvimos otro recurso en hacer uso de nuestras armas en nuestra defensa y para atemorizarlos. Hasta el momento ocho a.m. sólo he podido tomar unos cuarenta entre hombres, mujeres e hijos. Faltando quienes deben de hallarse bien en la costa de los montes del Paraguay o en los montes de esta costa, por lo que ruego se sirva impartir sus órdenes a fin de que sean capturados y remitidos inmediatamente a este establecimiento (cit. en Cambas y Ferrier 1991).

21 Las repercusiones de la fuga de los tobas en mayo de 1888, y especialmente de su desmedida represión, llegaron hasta el Congreso Nacional. El diputado bonaerense Juan Carballido pidió la interpelación del ministro de Guerra, Carlos Pellegrini, por los hechos denunciados por la prensa en Misiones (Diario de Sesiones de la Cámara de Diputados, 15/6/1888; Lenton 2005).

22 Un mes después se produjo la rebelión que dio origen al documento que nos interesa en esta oportunidad. Y en 1890, se habría producido otra revuelta de menores proporciones (Cambas y Ferrier 1991). En todos los casos, los rebeldes fueron perseguidos y reprimidos; $\mathrm{y}$ a veces, llevados de vuelta al ingenio.

23 La llamada "sublevación de los pampas", tal como la nombra la memoria local, se produjo el 23 de junio de 1888, según se consigna en el "Sumario levantado con motivo de la sublevación i fuga de los indios pampas que trabajaban en el establecimiento del Señor General Don Rudecindo [Roca]" (Archivo General de la Gobernación de Posadas). 

junio de 1888, día siguiente a la sublevación. Ellos son: Jordan Hummel (mayordomo), Guillermo Almeida (encargado de la proveeduría), Esteban Daneri (cocinero), Juan Centeno (peón pampa), Juan Chavanne (ingeniero), Guillermo Gouchard (mecánico), Anastasio Valdéz (azucarero), Patricio Salas (herrero), Francisco Estrada (empleado), Arturo Kirschner (agrimensor), Juana Fernandez (esposa de E. Daneri), Ignacio Borja (peón), Secundina Achiar (esposa de J. Hummel), Cirilo Ríos (capataz), Nemesio Cepeda (Sargento de Policía), Salvador Lentini (comerciante de Santa Ana) y Vicente Baez (dependiente de comercio en Santa Ana).

$$
\text { dañado, en especial la carátula, de la que solo quedaba la mitad superior y las primeras }
$$
páginas. escritos por la misma persona, y siempre suscriptos por el juez de paz de Santa Ana, José Mujica y dos testigos de la actuación: Manoel A. de Oliveira y Reginaldo I. Krieger. Recién al finalizar el expediente se presentan otros escribientes, que son quienes lo tramitan en Posadas, y finalmente, el Juez Nacional del Territorio, Darío Quiroga.

El texto presenta pocas enmiendas y tachaduras; estas parecen aumentar en proporción al rango del declarante, sugiriendo un grado mayor de autocensura en relación a la responsabilidad por las consecuencias de la rebelión.

31 La serie de las declaraciones ante el juez Mujica va desplegando un texto en el que a medida que se suceden los personajes, se nos permite también acceder a nuevos detalles de los sucesos del 23 de junio de 1888. Los hechos se narran desde diecisiete perspectivas diversas pero complementarias, permitiéndonos vislumbrar las tensiones existentes entre los distintos empleados jerárquicos, peones, comerciantes y sus esposas, que convivían en el ingenio. Las declaraciones presentan pocas contradicciones, y los dichos de unos ratifican, aun desde otro ángulo, los de otros. Las mayores disidencias se presentan en relación al rol desempeñado por el mayordomo Hummel, tanto en relación al trato con el personal indígena y criollo, como en relación a la propia eventualidad de la sublevación. 

xenófobo hasta la relativa empatía. Existen indicios de actitudes de cercanía entre los pampas prisioneros y algunos empleados, como el cocinero Daneri, que llegaban a estar enterados del malestar de los pampas previo al levantamiento, o el mecánico Gouchard, a quien los jefes pampas buscaban insistentemente antes de escaparse, probablemente para lograr ayuda - tal vez forzada - en la reparación de la embarcación en la que escaparían y que estaba averiada. Por otra parte, los jefes de la rebelión discriminan en su trato entre las diferentes personas a cargo del ingenio, y en general muestran tener cuidado en no infligir daños físicos al personal, con excepción de la partida policial. Casi todos los testigos demuestran conocer a una parte de los pampas por su nombre propio, y se relata también el conocimiento que los pampas tenían del personal criollo.

base a los testimonios se puede reconstruir que la revuelta comenzó a la hora del almuerzo, cuando los trabajadores pampas del ingenio se apropiaron de machetes, hachas y "Remingtons" que sumaron a lanzas, boleadoras y hondas propias, y lograron así amedrentar al personal. Los relatos coinciden en que la dirección de los hechos correspondió a Yancamil, Melideo y a su grupo cercano (entre ellos un hermano de Yancamil llamado Simón), a los que se sumaron los otros trabajadores y familias, totalizando 262 los fugados. ${ }^{15}$

También hay coincidencia en el alto nivel de organización previa del levantamiento, manifiesto en la división de tareas y en el cálculo apropiado de los tiempos necesarios para el traslado de todos los participantes. Melideo con los más ancianos, las mujeres y niños, cruzaron el río en los "vapores" Huáscar y Fénix, pertenecientes al ingenio, y luego de dejarlos en la costa paraguaya caminaron hacia el norte, llevando como rehenes a dos peones que lograron escapar días después y retornar a Santa Ana desde Encarnación. Mientras tanto, un grupo más pequeño capitaneado por Simón cuidaba la retaguardia dentro del ingenio, siendo los últimos en salir. Por su parte, Yancamil avanzaba hacia el este por la costa argentina con el grueso de los hombres y algunas familias, llevando algunos rehenes más, entre empleados del ingenio, dos mujeres y varios niños, haciendo sucesivas paradas donde dejaba puestos de vigilancia, sincronizando con la canoa que hacía el cruce de a veinte personas hacia la orilla opuesta. Mientras tanto, un par de "rezagados" espiaban los movimientos de la policía en el centro de Santa Ana, y cuatro jóvenes retenían a todos los caballos del ingenio dentro de la cabaña para que no pudieran ser utilizados en su persecución. El sargento de policía Nemesio Centeno declaró que ese día 23 de junio no se encontraba en Santa Ana hasta varias horas después de la fuga, porque lo habían mandado al arroyo San Juan a perseguir a cuatro pampas que se habían fugado en la noche anterior, en lo que probablemente fue una acción distractiva planificada.

El juez Mujica se preocupó por preguntar a todos los testigos si conocían las causas de la sublevación, y si podría haber existido una influencia o directiva externa. Varios testigos respondieron que estaban en conocimiento de los maltratos sufridos por los "pampas", y que la revuelta se habría desencadenado cuando el mayordomo Hummel intentó hacer trabajar en la caña a las mujeres, rompiendo una promesa previa. Algunos recordaron que Yancamil había protestado por ciertos abusos en el peso de las mercaderías en el boliche. Respecto de la segunda pregunta, todos coincidieron en que los pampas no tenían ningún contacto con "ninguna persona de fuera del Establecimiento, pues además de tener pocas relaciones, eran contadas las veces que ellos salían á pasear, especialmente Yancamil, que [por sus antecedentes] era el más sujeto de todos los indios" (Folio 7). 

contribuir a la discusión acerca de la magnitud y la variedad de situaciones que implicó lo que se conoció como el "reparto de indios" tras la conquista militar de la Pampa y Patagonia norte. En tanto se ha demostrado suficientemente la estrecha relación entre el aprisionamiento de la población indígena en edad activa como consecuencia de las incusiones militares, y su posterior separación, clasificación, distribución y explotación con fines económicos (Mases 1987, 2002; Conti et al. 1988; Iñigo Carrera 1988; Lenton 2005; Delrio y Escolar 2009), subsisten interrogantes acerca de la cotidianeidad de los espacios donde se producía dicha explotación, del grado de planificación previa de las políticas que sustentaron, y de las relaciones interpersonales e intergrupales que fueron su condición de posibilidad (Papazian, Musante y Perez 2014; Nagy y Papazian 2011; Lenton et al. 2011).

En el expediente queda evidenciado que la revuelta dejó solo una víctima fatal indígena, y del lado adverso solo tres heridos (el maquinista de una de las embarcaciones, un foguista y un peón). Yancamil como "autores y Gefes de un complot" (Folio 50). Previamente, se interroga a dos comerciantes del pueblo de Santa Ana que fueron visitados en días cercanos a la sublevación por clientes pampas que ostentaban dinero de Paraguay, aunque las fechas declaradas por estos testigos no permiten confirmar si esto tiene relación con la sublevación del 23 de junio.

\section{Comentarios finales}

La rebelión de 1888, pese a su persistencia en la memoria santanera como "la sublevación de los pampas" o "el malón pampa", ${ }^{16}$ no fue la primera ni la última que se produjo en el ingenio de R. Roca. ${ }^{17}$ En todos los casos, el objetivo no es la modificación de las condiciones de vida o de trabajo, sino la huida. en el recuerdo de la revuelta del mes siguiente solo puede atribuirse al desusado éxito y a la magnitud de la fuga, basados en la buena organización y la "destreza militar" de los líderes. No debe subestimarse el peso de la contraparte empresaria, dueña de su propia mítica, en el proceso que construyó el mito popular de la fuga de los pampas del ingenio.

indios "pampas" del establecimiento, más algunos aliados, evidenciando, además de un alto grado de planificación, la solidez de un liderazgo que excedía ampliamente la coyuntura de la huida. También debe destacarse como característica del liderazgo tradicional: la díada de líderes, en este caso Yancamil y Melideo, que actúan como socios inseparables, atravesando las distintas etapas de su biografía. de su exilio, cuando su grupo familiar y el mundo que había conocido y en el que ostentaba un lugar social privilegiado, ya no existían. ${ }^{18}$

El caso del ingenio San Juan parece representar una posición extrema en torno a la explotación y la represión, más apegada al carácter de prisioneros de estos destinados, que al de trabajadores. Los "indios de trabajo" están acompañados por sus mujeres, hijos, y por ancianos e "inválidos" o "enfermos", es decir por una alta proporción de población 
que no es contabilizada como activa. Más allá de que este entorno familiar cumple funciones ya conocidas en la reproducción de la fuerza de trabajo, es probable que el traslado grupal respondiera a las características del proceso de captación de esta mano de obra, más apegado al contexto de la circulación de prisioneros que a la racionalidad laboral.

Por otra parte, la circunstancia de la presencia en este ingenio de grupos familiares enteros con sus propios jefes, los cuales además traían una larga historia de acciones militares y sociales compartidas, permitió sin duda el diseño de un plan sofisticado de huida, como no se ha visto en otras fugas de establecimientos similares, además de aportar a la cohesión de los participantes. Así, la agencia indígena se manifestó espectacularmente en esta instancia, pero contó para su desarrollo con la agencia caracterizada por un empresario político-militar que maximizó su capacidad de influencia para lograr el acceso a una masa trabajadora extraordinaria para su emprendimiento. La rebelión de los pampas fue la consecuencia indeseada de la ambición de Rudecindo Roca.

El expediente de la fuga en sí mismo también configura un caso claramente excepcional, frente a la escasez de documentación sobre las condiciones de existencia de los indígenas en sus lugares de repartimiento, constituida por lo general por fuentes gubernamentales indirectas (que nos brindan información sobre acciones de gobierno cuya documentación, sin embargo, suele estar ausente de los mismos archivos), y por unas pocas crónicas periodísticas, eclesiásticas o literarias. Este rasgo extraordinario - junto con otros que ameritan un análisis más extenso que el que este espacio nos permite- contribuye a aumentar el valor de este documento para la discusión sobre el destino de los pueblos pampeanos y norpatagónicos expulsados de sus territorios.

Abbona, A. E. (2013). "El hombre a todo se amolda": territorio y trayectorias de incorporación subordinada de indígenas en La Pampa. El caso de José Gregorio Yankamil, 1900-1980. Memoria Americana [online]. 2013, n. 21-1. http://www.scielo.org.ar/ scielo.php?script=sci_abstract\&pid=S1851-37512013000100001

Alcaraz, M. (Comp.) (2008). Ranqueles, el grito mudo de la tierra. San Luis: Payne.

Ambrosetti, J.B. (2008 [1892, 1893, 1894]). Viaje a las Misiones argentinas y brasileras en el Alto Uruguay. Revista del Museo de La Plata, tomos III (1892), IV (1893) y V (1894); reeditado por Editorial Albatros, Buenos Aires (2008).

Bourgoing, A. (1894). Viajes en el Paraguay y Misiones: recuerdos de una expedición a los yerbales de Concepción, Cerro-Corá y Sierras de Amambay, etc. Buenos Aires: Tipografía, Litografía y Enc. La Velocidad.

50 Cambas, G. y Ferrier, M. R. (1991). Los indios de Roca. Ponencia en XI Jornadas de Geohistoria Regional, UNAM, Posadas, 13 de septiembre de 1991.

51 Campi, D. (Comp.) (1992). Estudios sobre la historia de la industria azucarera argentina, San Salvador de Jujuy. UNJu-UNT, 1991/1992, vols. 1 y 2.

52 Conti, V. A., Teruel de Lagos, A. y Lagos, M. (1988). Mano de obra indígena en los ingenios de Jujuy a principios de siglo. Colección Conflictos y Procesos de la Historia Argentina Contemporánea, 17, CEAL, Buenos Aires.

53 Delrio, W. (2005). Memorias de expropiación. Sometimiento e incorporación indígena en la Patagonia (1872-1943). Bernal: Editorial de la Universidad Nacional de Quilmes. 

Buenos Aires. Aires.

Delrio, W. y Escolar, D. (2009). Trayectorias y memorias de la diáspora forzosa de prisioneros indígenas entre Patagonia y Cuyo, S. XIX-XX. XII Jornadas Interescuelas/ Departamento de Historia. San Carlos de Bariloche, octubre de 2009.

Depetris, J. C. (1992). Confinamiento de pampas y ranqueles en los ingenios de Tucumán. Todo es Historia, 295, enero 1992, Buenos Aires.

Depetris, J. C. y Vigne, P. (2000). Los Rostros de la Tierra. Iconografía indígena de La Pasma. 1870-1950. Santa Rosa: Amerindia, Universidad Nacional de Quilmes.

Depetris, J. (2002). El destino de la comunidad ranquel. Revista Primero de Octubre, 42, Santa Rosa, La Pampa, octubre 2002.

Escolar, D. y Saldi, L. (2016). ¿Castas invisibles de la nueva nación?: los prisioneros indígenas de la Campaña del Desierto en el registro parroquial de Mendoza. En W. Delrio, D. Escolar, D. Lenton y otros (Eds.), En el país de nomeacuerdo. Archivos y memorias del genocidio del estado argentino sobre los pueblos originarios (1870-1950). Viedma: Universidad Nacional de Río Negro (en prensa).

Guerra, M. O. (1979). Crónica de los gobernantes de Misiones. Tomo I (1882-1922). Posadas: Instituto Antonio Ruiz de Montoya.

Gutiérrez, C., Wellbach, E. y Octacio, M. (2010). Revolución Industrial y trabajo precapitalista: el caso del ingenio San Juan, Santa Ana, Misiones. XXII Jornadas de Historia Económica, Río Cuarto (Córdoba), 21-24 de septiembre de 2010.

Gutiérrez, C., Wellbach, E. y Octacio, M. (2014). ¿Desarrollo ausente o trunco? Historia del no desarrollo de Santa Ana. Segundo Informe de Avance, 10 de julio de 2014, UNaM, FHyCS. Disponible en: http://argos.fhycs.unam.edu.ar/handle/123456789/459. Recuperado el 2 de febrero de 2016.

2 Holmberg, E. L. (1887). Viaje a Misiones. Boletín de la Academia Nacional de Ciencias, Tomo X,

Hux, M. (1991). Caciques Pampa-ranqueles. Buenos Aires: Ed. Marymar.

Iñigo Carrera, N. (1988). La violencia como potencia económica: Chaco 1870-1940. Colección Conflictos y Procesos de la Historia Argentina Contemporánea, 11, CEAL, Buenos

5 Lenton, D. (2005). De centauros a protegidos. La construcción del sujeto de la política indigenista argentina desde los debates parlamentarios $(1880-1970)$. Tesis Doctoral en Ciencias Antropológicas, Facultad de Filosofía y Letras, UBA. Reproducida en Revista Corpus-Archivos Virtuales de la Alteridad Americana, 4 (2), Julio-Diciembre de 2014. URL: https://corpusarchivos.revues.org/1290. (Recuperada el 2 de febrero 2016).

Lenton, D., Tamagno, L., Seldes, V., Roulet, F., Garrido, M. T., Pérez, P., Delrio, W., Ramos, A., Escolar, D. y Vezub, J. (2011). Genocidio y política indigenista: debates sobre la potencia explicativa de una categoría polémica. Dossier. En Corpus [En línea], 1 (2) 2011, Publicado el 30 diciembre 2011. URL: http://corpusarchivos.revues.org/1148; DOI: 10.4000/corpusarchivos.1148. Recuperada el 12 de noviembre de 2016.

67 Lenton, D. y Sosa, J. (2016). De la Frontera Sur a Tucumán y Misiones: Itinerarios de los prisioneros hacia los ingenios azucareros. En W. Delrio, D. Escolar, D. Lenton y otros (Eds.), En el país de nomeacuerdo. Archivos y memorias del genocidio del estado argentino sobre los pueblos originarios (1870-1950). Viedma: Universidad Nacional de Río Negro (en prensa). 
Mases, E. H. (1987). Sistema de distribución de indígenas. Ubicación en la sociedad global. III Jornadas de capacitación y perfeccionamiento docente: La cuestión indígena en la historia argentina, Instituto de Investigaciones Históricas del Museo Roca, Buenos Aires, septiembre de 1987.

Mases, E. H. (2002). Estado y cuestión indígena. El destino final de los indios sometidos en el fin del territorio (1878-1910). Buenos Aires: Prometeo libros/Entrepasados.

Nagy, M. y Papazian, A. (2011). El campo de concentración de Martín García. Entre el control estatal dentro de la isla y las prácticas de distribución de indígenas (1871-1886), Corpus [En línea], Vol 1, No 2|2011, URL: http://corpusarchivos.revues.org/1176; DOI: 10.4000/corpusarchivos.1176

71 Nagy, M. y Papazian, A. (2016). De todos lados, en un solo lugar. La concentración de indígenas en la isla Martín García. (1871-1886). En W. Delrio, D. Escolar, D. Lenton y otros (Eds.) En el país de nomeacuerdo. Archivos y memorias del genocidio del estado argentino sobre los pueblos originarios (1870-1950). Viedma: Universidad Nacional de Río Negro (en prensa).

2 Papazian, A., Musante, M. y Perez, P. (2014). Los campos de concentración indígena como espacios de excepcionalidad en la matriz estado-nación-territorio argentino. En J. L. Lanata (Comp.) Prácticas Genocidas y Violencia Estatal en Perspectiva Transdisciplinar, IIDyPCaCONICET.

Pérez, P. (2007). Represión y resistencia: una aproximación a los campos de concentración en el territorio patagónico a fines del siglo XIX. II Encuentro Internacional Análisis de las Prácticas Sociales Genocidas, Universidad Nacional de Tres de Febrero, Buenos Aires.

Pérez, P. (2016). Archivos del silencio. Estado, indígenas y violencia en Patagonia Central 1878-1941. Buenos Aires: Ed. Prometeo.

5 Pérez Zavala, G. (2012). Reparto de indígenas en Río Cuarto (1870-1890): consideraciones preliminares. Revista TEFROS, 10 (1-2), Primavera 2012, Río Cuarto. Disponible en: http:// www.hum.unrc.edu.ar/ojs/index.php/tefros/article/view/248/229

6 Pucci, R. (1986). Tucumán, 1880-1917: su estructura económico-social. Pautas para una interpretación del 'despegue' azucarero. Cuadernos de Historia Regional, 5 (2), Universidad Nacional de Luján, abril de 1986.

77 Pucci, R. (1989). La élite azucarera y la formación del sector cañero en Tucumán (1880-1920). Colección Conflictos y procesos de la Historia Argentina Contemporánea, 37, Buenos Aires: Centro Editor de América Latina. carbón y del azúcar. Buenos Aires: Ed. Ariel. Rosenzvaig, E. (1986). Historia Social de Tucumán y del azúcar. Tomo 2: El Ingenio. San Miguel del Tucumán: Universidad Nacional de Tucumán.

30 Teruel de Lagos, A. (1991). Regulación legal del trabajo en las haciendas, ingenios y plantaciones de azúcar en la Provincia de Jujuy, siglo XIX a mediados del siglo XX. Estudios sobre la historia azucarera argentina, (1). San Miguel de Tucumán: UNT.

1 Fuentes primarias

82 Diario de Sesiones de la Cámara de Diputados de la Nación, 24/8/1885 y 15/6/1888. Biblioteca del Congreso Nacional.

Diario La Nación, 16 de noviembre de 1878. Biblioteca Prebisch, BCRA. 
Sumario levantado con motivo de la sublevación i fuga de los indios pampas que trabajaban en el establecimiento del Señor General Don Rudecindo [Roca]. Archivo Judicial de la Gobernación, Posadas, Provincia de Misiones.

\section{Anexo : Transcripción del documento}

\section{Archivo General de la Gobernación de Posadas}

\section{Leg. 174. Año 1888. Sumario levantado con motivo de la sublevación i fuga de los indios pampas que trabajaban en el establecimiento del Sr. Don Rudecindo (...)}

\section{Folio 1}

Auto cabeza del proceso.

Habiendo llegado a mi conocimiento en el día de ayer por aviso de Don Jordan Hummel, que los indios Pampas que trabajaban en el Establecimiento Azucarero del Señor General D. Rudecindo Roca se habian sublevado, saqueando el negocio que en dicho establecimiento existe (...) apoderándose de los vaporcitos y canoa que existían en el puerto, i herido á varias personas, llevándose en su fuga a otras, debía mandar i mando para el esclarecimiento de estos hechos que se proceda a la instrucción del correspondiente sumario, constituyendo en prisión á los autores i complices de este hecho.

Y por este auto

\section{Folio 1 reverso}

cabeza de proceso así lo proveo i mando i firmo yo el Juez de paz del Distrito por ante los testigos que suscriben en Santa Ana al veinte i cuatro de Junio de mil ochocientos ochenta i ocho. José A. Mujica

91 Juez de Paz

\section{Testigo Manoel A. de Oliveira}

Testo. Reginaldo I. Krieger

En veinte i cuatro del mismo compareció ante mí i testigos con quien actúo el mayordomo del Establecimiento Azucarero del Señor General Roca, D. Jordan Hummel, á quien recibí juramento que prestó en forma i en merito del cual se obligaba a decir verdad en todo lo que supiera i fuese interrogado, siéndolo en consecuencia al tenor de las siguientes preguntas.

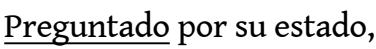




\section{Folio 2} auxilio de su mujer, mientras el declarante se dirigia apresuradamente a la Fábrica a ponerse al frente de los hombres que allí tenía reunidos y cuyo número no pasaba de veinte, todos ellos desarmados. Que en estas circunstancias y cuando el declarante con los hombres que había reunido en la fábrica se disponía a salir en auxilio de los atacados por los indios sublevados, fue rodeado a su vez por un grupo de éstos en número como de veinte i cinco ó treinta, armados con lanzas, machetes y boleadoras que le cerraban el paso en actitud hostil. Que en este momento el indio Centeno que también estaba con el declarante, consiguió con amenazas que los indios sublevados que les cerraban el paso le per-

\section{Folio 3 reverso}

-mitieran venir a su casa, a la casa donde está el negocio i demas dependencias de la Administración donde se encontraba Melideo con el grueso de los indios sublevados, sus mujeres é hijos con el propósito de ver si podía apaciguar la sublevación. Que logrado esto, el declarante se puso en camino para dichas poblaciones acompañado de los peones que tenia reunidos alcanzando apenas a llegar al depósito de la locomotora donde nuevamente fue atacado por la mayor parte de los indios que como ha dicho se 
encontraban reunidos en la plazoleta que forman las varias dependencias del establecimiento con la costa del río, resultando heridos en este encuentro el foguista Manuel Villaveo y Ciriaco Rodriguez, el primero de un hachazo en la mano i el segundo de un golpe de bolas en el pecho. Que desde este sitio i durante el poco

\section{Folio 4}

tiempo que en él pudo permanecer antes de ser atacado, vio que los indios sublevados juntamente con sus mujeres, impulsados a gritos por Melideo sacaban en atados, del negocio, las existencias que en él había, así como las armas i herramientas que habia en casa del declarante y que consistian en tres remington y estima en treinta machetes nuevos de los ultimamente recibidos para el corte de la caña. Que al regresar a la Fabrica por el mismo camino del Ferro-carril que habia traido, se encontró con el grupo de indios capitaneado por Yancamil, que venían por el camino de abajo buscando la incorporación de los otros indios, i que traian prisionero al capataz Cirilo Rios que con tal motivo el declarante le dirigió la palabra a Yancamil pidiendole que largara a Rios a lo que este

\section{Folio 4 reverso}

102 le contestó enfurecido que no solo no largaría a Rios sino que iba á volver en busca de él, que lo aguardara. Que momentos despues de reunidos estos indios á los que habian saqueado el negocio i demás poblaciones del establecimiento, vio á Yancamil que con los otros indios le llevaba tambien presa a la mujer que vive con el declarante, asi como a un hijito de un año i meses de edad, encerrándolos en el cuarto de la bomba. Que en estas circunstancias i considerado por el declarante toda tentativa tendiente a imponerse a los indios sublevados, no solo porque estos se encontraban en mayor número i todos ellos perfectamente bien armados i decididos a llevar por delante cuanto se opusiera a sus designios de robar y fugarse, mandó dar cuenta de lo ocurrido al Juzgado, mientras él se

\section{Folio 5}

103 dirigia a la Cabaña, de donde también le salieron al encuentro amenazandolo con matarlo los cuatro indios que habia allí al cuidado de los animales yeguarizos. Que en esta situación viendose amenazado por todos lados se vio obligado á buscar su salvacion en la fuga por entre los montes hasta llegar al establecimiento de don Enrique Puck de donde regresa hoy. Que juntamente con el declarante iba también el encargado del negocio D. Guillermo Almeida.

104 Preguntado si la mañana de ayer no tuvo aviso de esta sublevación, dijo: que no. Que el aviso que tuvo le fue dado por Centeno como ha manifestado yá casi a la misma hora en que se producia la sublevación, es decir, a la una i mi-

\section{Folio 5 reverso}

-nutos de la tarde, pues que de haberlo sabido antes habria tomado las medidas del caso. 
106 Preguntado en qué consisten los robos perpetrados por los indios sublevados, dijo: que hasta el momento según se ha podido notar ellos consisten en diversos artículos de tienda i almacen de la casa de negocio, en armas i machetes que existian en la casa del declarante, $i$ en un traje completo de casimir del ingeniero Señor Juan Chavannes, sin contar algunas cajas de cartuchos a bala para carabina de salón, de uso del Señor General Roca.

107 Preguntado qué número de indios son los fugados i cual era el empleo que ellos tenian en el establecimiento, dijo: que los indios fugados son doscientos cuarenta i nueve, entre

\section{Folio 6}

hombres, mujeres i niños, siendo de estos ciento treinta i tres de trabajo, empleados en las distintas faenas del Establecimiento i sus dependencias, diez i ocho entre ancianos e inválidos por enfermedades crónicas, que por consiguiente no prestaban ningún servicio, contándose entre este número a Melideo; cuarenta y nueve mujeres y cuarenta y nueve criaturas de ambos sexos. Que todos estos indios e indias eran diariamente racionadas de carne, arroz, sal i maiz, porotos, cuando no habia maiz, en la propoción del numero de personas de que se componía cada grupo. Que en cuanto a los indios de trabajo, además del alimento mencionado se les pagaba religiosamente sus sueldos, suministrándoseles a los ancianos inválidos

\section{Folio 6 reverso}

como a los mismos trabajadores la ropa que necesitaban.

Preguntado si tiene conocimiento ó presume que causa ha motivado la sublevación de los indios dijo: que no. Que lo que únicamente sabe es lo que Yancamil le dijo á la mujer del declarante cuando la llevaba presa, i es que estaba disgustado con el declarante porque de algún tiempo á esta parte los apuraba mucho en el trabajo. Que por lo que respecta especialmente a Melideo y Yancamil el declarante los ha tratado siempre con las mayores consideraciones cumpliendo las órdenes que al efecto tenía recibidas del Señor General Roca, entregándose a Yancamil en cumplimiento de dichas

\section{Folio 7}

ordenes, la suma de cinco pesos moneda nacional por semana.

Preguntandole si tiene conocimiento de que Melideo i Yancamil mantuvieran relaciones íntimas i frecuentes con personas de fuera del establecimiento, dijo: que no. Que ninguno de fuera llegaba al rancho de estos, ni los referidos indios se trataban intimamente con ninguna persona de fuera del Establecimiento, pues además de tener pocas relaciones eran contadas las veces que ellos salían a pasear, especialmente Yancamil que era el mas sujeto de todos los indios. Que lo que unicamente puede decir al respecto, es que dos dias antes de la sublevacion el declarante lo encontró a Melideo en momentos en que salía del cuarto de Esteban Daneri en un esta- 


\section{Folio 7 reverso}

113 leída que le fue al declarante se afirmó i ratificó en su contenido firmando con los testigos
por ante mi de que certifico = entre líneas = por = en este encuentro = Vale.

114 José A. Mujica

115 Juez de Paz

116 Jordan Hummel

117 Testigo Manoel A. de Oliveira

118 Testigo Reginaldo I. Krieger

119 En la misma fecha compareció ante mi i testigos con quienes actúo, Don Guillermo Almeida llamado a declarar en esta causa, quien previo juramento de ley que prestó en forma en merito del cual se obligaba a decir verdad en todo lo que supiere i fuese pre-

\section{Folio 8}

-guntado, fue examinado al tenor de las siguientes preguntas.

121 edad, de estado soltero, comerciante de profesion i que tiene su domicilio en el ingenio Azucarero del Señor General Don Rudecindo Roca donde actualmente vive.

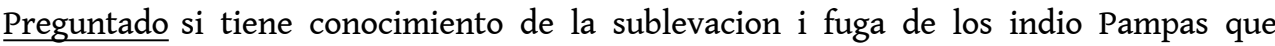
trabajaban en el establecimiento de dicho sr. General, ocurrida en el dia de ayer dijo: que como a la una del dia de ayer, hora en que presisamente vuelven al trabajo los peones del establecimiento después del almuerzo y descanso de mediodia, i en circunstancias en que el declarante se hallaba almorzando en la trastienda del negocio, que en di-

\section{Folio 8 reverso}

-cho ingenio administra como encargado, recibió aviso del Señor Jordan Hummel, mayordomo del Establecimiento de que estuviera prevenido porque habia sabido en aquellos momentos que los indios Pampas debían sublevarse con propósitos hostiles, que inmediatamente de recibir este aviso el declarante mandó un peón a la Fábrica en busca de un remington que le habia prestado al ingeniero mecánico de ella D. Guillermo Gouchard, que de regreso el peon con el remington y con el fin de buscar unos tiros el declarante abrió una puerta del negocio que hasta entonces permanecia cerrada como de costumbre, á la hora de comer, siendo inmediatamente invadido por un numeroso grupo de indios armados i capitaneados por Simón, hermano de Yan-

\section{Folio 9}

124 -camil, quienes con empujones y amenazas de muerte lo obligaron a salir afuera. Que en estas circunstancias i en la imposibilidad de hacer algo el declarante se dirigió a la Fábrica donde se encontraba reunido un grupo de peones del establecimiento con el Señor Jordan 
a la cabeza, mirando desde ahí el saqueo del negocio, ejecutado por los indios, asi como el de las otras poblaciones que se encuentran próximas a este, i a la administracion. Que además del saqueo, presencio tambien desde la Fábrica cuando Yancamil con otros indios llevaban preso al capataz Cirilo Rios y posteriormente cuando el mismo Yancamil conducia presa al cuarto de la bomba a la mujer e hijo del señor Jordan. Que despues de un momento de per-

\section{Folio 9 reverso}

-manencia en la Fábrica i teniendo fundadamente en vista de estos hechos como de los que momentos antes se habian producido en el deposito de la locomotora, entre el Señor Jordan i algunos peones que lo acompañaban con un grupo de indios que salieron á pelearlo hiriéndole dos peones, temiendo vuelva a repetir que los indios sublevados pusieran en ejecución su plan de esterminio, el declarante buscando su salvación en la fuga, se fue al monte por entre el cañaveral acompañado del Señor Hummel. Que á la altura de la cabaña fueron atacados por los cuatro indios que allí habia encargados del cuidado de las yeguas, dos de los cuales estaban armados de remington por cuyo motivo tanto el declarante como el señor Jordan, tuvo que in-

\section{Folio 10}

-ternarse al monte siguiendo en dirección al establecimiento del Sr Puck de donde viene hoy.

Preguntado si tiene conocimiento de que Melideo i Yancamil mantuvieran relaciones íntimas i frecuentes con personas de fuera del establecimiento, dijo: que no.

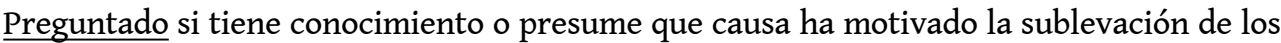
indios, dijo que no.

Preguntado en que consisten los robos perpetrados por los indios, dijo: que por lo que respecta al negocio del cual estaba encargado el declarante el robo ejecutado por los indios en dinero efectivo i articulos de tienda y almacén lo estima en mil pesos moneda nacional mas ó menos, sin contar un baul de ropa blanca i de color de uso i propiedad del declarante. Que

\section{Folio 10 reverso}

en cuanto a los otros robos consisten en tres remingtones, treinta machetes vizcainos nuevos que se encontraban en casa del Señor Jordan i algunos objetos del ingeniero señor Chavanne y señor General Roca, cuyo detalle no puede determinar.

Con lo que se dio por terminada la presente declaración y leída que le fue al declarante se afirmó i ratificó en su contenido firmando con los testigos por ante mi de que certifico = entre renglones $=$ previo $=$ Vale .

133 Juez de Paz

134 Guillermo Almeida 

indios que habia alli, le habian quitado el remington i balas que tenia. Que entonces el

Daneri, testigo llamado á declarar en esta causa quien previo juramento de ley que prestó en forma, fue examinado al tenor de las siguientes preguntas.

Preguntado por su edad, estado, profesion y domicilio, dijo, que tiene veinte i nueve años de edad de estado soltero, cocinero de profesión y tiene su domicilio en el establecimiento Azucarero del señor General D. Rudecindo Roca.

Preguntado si tiene conocimiento de la sublevación y fuga de los indios Pampas que trabajaban en el ingenio del dicho señor General, acaecidos en el día de antes de ayer, como se produjo el hecho, cuándo y de que manera dijo: que el mencionado día de antes de ayer, veinte i tres, como a eso de las diez á once de la mañana, el indio Juan Centeno le dio aviso al declarante de que los indios

\section{Folio 11 reverso}

Pampas se iban a sublevar, que entonces el declarante le dijo al referido indio Centeno que inmediatamente fuera á poner el hecho en conocimiento del mayordomo del Establecimiento Señor Jordan Hummel. Por cuanto él mismo no podía hacerlo en razón a que hacía tiempo que el dicho mayordomo, cada vez que iba a darle cuenta de algo, lo echaba á pasear con palabras altamente ofensivas, á lo que Centeno le contestó que ya le había dado parte también a Jordan, de la sublevación pero que este parecía que no le había hecho caso por cuanto cuando le dio el aviso movió los hombros y le dio la espalda. Que entonces el declarante insistió pidiendole á Centeno que fuera nuevamente á darle parte del hecho a Jordan, como lo hizo por ser él el mayordomo, i por

\section{Folio 12}

consiguiente la única persona que podía tomar medidas en este caso. Que despues de esto, i pasado un momento, Jordan le mandó decir al declarante que metiera dentro del galpón unos cueros vacunos que estaban en el patio y que hacia poco habian sido tomados de la estancia. Que con este motivo y pidiendole el declarante al mencionado Jordan que le proporcionara unos peones para hacer el trabajo ordenado por él, por cuanto solo le era imposible hacerlo, dicho señor le contestó de mal modo echándolo nuevamente a pasear. Que visto esto i en el deseo de evitar un conflicto personal con dicho señor mayordomo, el declarante se resolvió mas bien á irse á Santa Ana despues de medio dia a poner estos hechos en conocimiento del Juez, cuando en el camino se encontró con un

\section{Folio 12 reverso}


declarante regreso apresuradamente al ingenio donde ya encontró sublevados a los otros indios i posecionados del negocio y demás dependencias de la Administracion. Que entonces dio su caballo al empleado Roque Roa para que fuera inmediatamente á dar aviso de estos hechos al Juzgado de Santa Ana, mientras el declarante se dirigia a la Fabrica donde vió reunidas algunas personas. Que llegado á la Fabrica se encontró allí con el azucarero don Anastasio Valdes i muchos peones del Establecimiento, entre ellos Manuel Villaveo que momentos antes había sido herido

\section{Folio 13}

por los indios quienes le dijeron que el mayordomo Señor Jordan se habia escapado por entre los cañaverales. Que desde la Fabrica i en la imposibilidad de llegar á las poblaciones i negocio que los indios saqueaban por cuanto en un momento que quiso hacerlo se le dijo que sería una temeridad por que lo iban a matar, vió á los indios sublevados que corrian con armas, palos i hachas de un lado a otro dando espantosos gritos. Que en estas circunstancias i en atención a la fuga del mayordomo, el declarante mandó al indio toba llamado Marincho a que trajera sus compañeros con machetes de trabajo que tenían, con el fin de prestar alguna protección a las personas que se habian guarecido en la Fábrica, entre los cuales se encontraban muchas mu-

\section{Folio 13 reverso}

-jeres. Que como una hora después de los hechos referidos es decir, como a eso de las dos ó dos y media de la tarde los indios sublevados se fueron los unos embarcados en la canoa y vaporcitos del Establecimiento, "Huascar" i "Fenix", llevándose prisioneros al capataz Cirilo Rios i Gabriel Florentin, i los otros por tierra siguiendo la costa en direccion al puerto conocido por "Puerto de Alves", llevandose prisioneras a la mujer i un hijo de pocos meses, del declarante i a la mujer e hijos del mayordomo señor Jordan, asi como al peon de la bomba llamado Ignacio Borja i la mujer del peon Antonio Barbosa. Que tan pronto el declarante i las personas que lo acompañaban tuvo la seguridad de que todos los indios sublevados se habian ido, vino a las poblaciones de la Administración, encontrándose con las

\section{Folio 14}

puertas rotas i todo lo que habia quedado en el mas completo desorden, asi como en las piesas que el declarante ocupa, rotas tambien las puertas i dos de sus hijos en completo estado de desesperacion. Que momentos despues llegó el Sargento de Policia del distrito D. Nemesio Cepeda, quien acompañado del peon del establecimiento Remigio Silva se dirigio adonde se suponia que debian estar los indios, con el fin de ver si podia rescatar los prisioneros; incorporándose instantes después al mismo Sarjento otros dos soldados de la misma policia llamados Fortunato Garcia i Tiburcio Collado.

Preguntado en que consisten los robos perpetrados por los indios dijo: Que los robos consisten según ha podido averiguar hasta estos momentos i según el mismo declarante vió cuando llegó a 


\section{Folio 14 reverso}

148 ellos

\section{Folio 15} medida $=$ Vale.

José A. Mujica

Juez de Paz

Esteban Daneri

la casa después de la ida de los indios, en todos los articulos de tienda i dineros de almacen que habia en el negocio del establecimiento i cuyo monto no puede precisar; en algunos hatos de grasa i el arroz que habia en un cajón del galpón; en ropas de uso del declarante y su familia; en ropas de uso i algunos objetos del General, como ser las cajas de balas de tiro de salon, i algunas ropas del ingeniero señor Chavanne, i de las armas i machetes que existian en casa del mayordomo Señor Jordan.

Preguntado si tiene conocimiento o presume que causa ha motivado ó podido motivar la sublevación de los indios, dijo: que positvamente no conoce las verdaderas causas de la sublevación de los indios, pero que los atribuye al descontento General que reinaba entre

á causa del mal-trato, que según el mismo Yancamil le dijo al declarante, les daba Jordán, i mui especialmente al hecho de haber hecho trabajar á las mujeres de estos indios en el corte de la caña. Que á propósito de esto el mismo Yancamil le dijo al declarante cuando estaba embarrando el galpón de los caballos que solo esperaba la llegada del señor General para poner en su conocimiento, tanto este como otros hechos que se cometían en el boliche, con el peso i medida de los artículos que compraban.

Preguntado si tiene conocimiento de que Melideo i Yancamil manteníaan relaciones íntimas i frecuentes con personas de fuera del establecimiento, dijo: que no.

Con lo que se dio por terminada la presente declaración que leída que le fue al declarante se afirmó i ratificó en su con-

\section{Folio 15 reverso}

- tenido firmando con los testigos por ante mi de que certifico. - Entre renglones $=\mathrm{i}$

Testigo Manoel A. de Oliveira

Testigo Reginaldo I. Krieger

Acto continuo compareció ante mi i testigos con quienes actúo, el indio pampa Juan Centeno, testigo llamado a declarar en esta causa quien previo juramento de ley que prestó en forma, fue examinado al tenor de las siguientes preguntas...

Preguntado por su edad, estado, profesion y domicilio, dijo: Que tiene cincuenta años de edad, de estado casado, de profesión peon del establecimiento del Señor General Roca donde tiene su domicilio.

Preguntado si tiene conoci- 


\section{Folio 16}

-miento de la sublevación y fuga de los indios Pampas que trabajaban en el ingenio del dicho señor General, acaecidos en el día de antes de ayer, como se produjo el hecho, cuándo y de que manera dijo: que en las primeras horas del día mencionado, veinte i tres del corriente, tuvo aviso reservado del indio Huincá, de que ese mismo día debían sublevarse todos los indios pampas que trabajaban en el establecimiento, i que por consiguiente al darle la noticia lo hacia solamente porque tuviera cuidado. Que en el momento vino á prevenirle a Esteban de dicha sublevacion, por no haverlo encontrado á Jordan, quien le dijo que inmediatamente fuera á avisarle á Jordan. Que cumpliendo esta orden, el declarante lo buscó i encontró a Jordan en momentos en que dicho Señor regresaba con la

\section{Folio 16 reverso}

locomotora del cañaveral, dandole aviso de la sublevacion de los indios que en aquel día debía tener lugar, á lo que Jordan le contestó “que estaba bueno”. Que momentos después de este aviso i cuando se producia la sublevacion, el declarante buscó i encontró a Jordan manifestandole que era su amigo i que como tal venía á pelear á su lado. Que consecuentemente con esto acompañó á Jordan i á los que con él venían hasta el depósito de la locomotora donde fueron atacados i rechazados por los indios sublevados hasta la Fábrica de donde el mencionado señor Jordan desapareció.

Preguntandole si tiene conocimiento de que Melideo i Yancamil mantenían relacion íntimas i frecuentes con personas de fuera del establecimiento, dijo: que no.

Preguntado si tiene conocimiento o presume que causa ha

\section{Folio 17}

motivado la sublevación i fuga de los indios, dijo: que no las conoce ni sabe a qué atribuirlas pues, por lo que respecta al sueldo $\mathrm{i}$ alimentos se les pagaba con puntualidad.

Con lo que se dio por terminada la presente declaración que leída que le fue al declarante se afirmó i ratificó en su contenido i habiendo manifestado que no sabía escribir i si solo hacer una cruz, lo hace en prueba de ello ante mi de que certifico = entre renglones $=\mathrm{i}$ rechazado $=\mathrm{i}$ encontró $=$ Vale.

Juez de Paz

170 [cruz]

Testigo Manoel A. de Oliveira

Testigo Reginaldo I. Krieger

Seguidamente compareció ante mi i testigos con quienes actúo, D. Juan Chavanne, testigo 


\section{Folio 17 reverso}

\section{Folio 18} en la casa. Que indios se habian fugado. domicilio.

\section{Folio 19}

-ta el origen de ella.

llamado a declarar en esta causa quien prévio juramento de ley que prestó en forma, fue examinado al tenor de las siguientes preguntas.

Preguntado por su edad, estado, profesion y domicilio, dijo: Que tiene treinta i un años de edad, de estado soltero, de profesión ingeniero, i domiciliado en el Establecimiento Azucarero del Señor General D. Rudecindo Roca.

Preguntado si tiene conocimiento de la sublevación y fuga de los indios Pampas que trabajaban en el establecimiento del señor General Roca, en el día de antes de ayer, como se produjo el hecho, cuándo y de que manera dijo: que como a la una de la tarde del día veinte i tres del corriente se hallaba el declarante en la casa que ocupa la administración, cuando súbitamente sintió una gran griteria que daban los indios, i habiendo salido fuera

de la habitacion, que se halla sobre la barranca del rio, vió un numeroso grupo de indios pampas todos armados de machete que se dirigían á la bajada que va al río donde se apoderaron de la canoa i de los vaporcitos que pertenecientes al Establecimiento se hallaban anclados en el embarcadero. Que acto continuo el declarante viendo el inminente peligro en que se hallaba i temiendo los desmanes que pudieran cometer los indios sublevados, determinó huir al cañaveral como lo verificó, no sin haber invitado antes á que hicieran lo mismo a la mujer de Estaban Daneri i sus tres hijos como igualmente á otra mujer i cinco criaturas que se hallaban en aquel momento en la habitación del declarante, sin que estas personas quisieran acompañarlo, permaneciendo

\section{Folio 18 reverso}

despues que el declarante ganó el cañaveral, donde permanecio escondido como dos horas, se dirigió por entre el mismo en direccion a la Fábrica, acompañado del vaqueano del vapor Huascar Teófilo López, al que habia encontrado en el cañaveral. Que cuando llegó a la Fábrica el declarante con su precitado compañero, serían las tres de la tarde, i allí supo por los demás empleados del establecimiento que todo habia terminado pues los

9 Preguntado en qué consisten los valores perpetrados por los indios dijo: Que solo sabe que al declarante le llevaron los indios un traje completo de casimir de la casa donde tiene su

Preguntado si tiene conocimiento o presume que causa ha motivado la sublevación de los indios, dijo. Que nada puede decir al respecto, pues no le cons- 

halló mas los indios, i al buscar el revolver en el sitio donde lo tenía no lo halló. Que entonces el compareciente buscó su salvacion en la fuga por entre los cañaverales donde 
tropesó con un grupo de indios armados que trataron de arrestarlo i de los que pudo evadirse, dirigiendose en dirección a Santa Ana; encontrando a poca distancia al peon del establecimiento Juan García á quien el declarante dijo lo condujese á Santa Ana á fin de dar parte al Señor Juez, á lo que Garcia le dijo que este último ya habia sido avisado. Que entonces el declarante le pidió á García lo llevase al establecimiento del Señor Puck., á lo que aquel accedió, i donde permaneció hasta el dia de ayer en que regresó al

\section{Folio 21}


en el depósito de la locomotora, no pudiendo distinguir entre quienes. Que en ese momento llegó el peon que habia mandado á su casa en busca del revolver quien le dijo que unos indios que habia encontrado en la puerta de la casa no le habian dejado entrar amenazándolo con unas bolas. Que entonces el declarante se dirigió a su casa donde ya no encontró quien le impidiera entrar a pesar de haber atravesado por

\section{Folio 22 reverso}

entre un grupo de indios armados con bolas, palos i machetes. Que una vez en su casa el declarante se encerró en ella afin de defender á su familia cosa que fuera atacado, i que desde allí vio pasar al capataz Cirilo Rios que lo llevaban prisionero, entre un grupo de indios, dirigido por Yancamil.

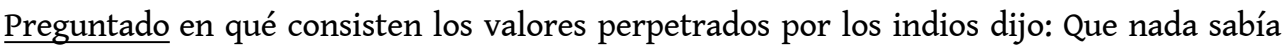
por que como ha dicho no habia salido de su casa durante el tiempo que duró el barullo.

210 Preguntado si tiene conocimiento o presume que causa ha motivado la sublevación de los indios, dijo que no.

211 Con lo que terminó la presente declaración i leída que le fue al declarante se afirmó i notificó en su contenido firmando

212 Folio 23

213 con los testigos por ante mi de quien certifico.

214 José A. Mujica

215 Juez de Paz

216 Anastasio Valdez

217 Testigo Manoel A. de Oliveira

218 Testigo Reginaldo I. Krieger

219 Seguidamente compareció ante mi i testigos con quienes actúo D. Patricio Salas, testigo llamado á declarar en esta causa quien previo juramento de ley que prestó en forma, fue examinado al tenor de las siguientes preguntas.

220 Preguntado por su edad, estado, profesion y domicilio, dijo: Que tiene sesenta i dos años de edad, de estado casado, de profesión herrero i que tiene su domicilio en el establecimiento azucarero del Sr. Gral. Roca.

221 Preguntado si tiene cono-

\section{Folio 23 reverso}

-cimiento de la sublevación y fuga de los indios Pampas que trabajaban en el establecimiento del citado General Roca, ocurrido en el día veinte i tres del corriente, como se produjo el hecho, cuándo y de que manera dijo: que el citado día veinte i tres, pasada la hora del mediodia hallábase el declarante en su casa almorzando cuando llegaron los indios pampas Santos, Simón i Yancamil preguntándole por el mecánico D. Guillermo Gouchard, i como no dieran crédito a lo que dijo el compareciente, de que éste no se hallaba en su casa registraron ésta i convencidos de que no se hallaba allí el que 
buscaban, le preguntaron si tenia algunas armas i como el declarante le manifestara de que no se marcharon. Que de allí a un momento volvió Santos solo preguntándole nueva-

\section{Folio 24}

-mente por el mecánico Don Guillermo, registrando otra vez la habitación y no encontrándolo se fue, volviendo un instante despues otra vez i previno al declarante que huyera de allí sin decirle el porqué. Que entonces el declarante se refugió en el edificio de la Fábrica, de donde sólo observo el movimiento incesante de los indios de un lado para otro, permaneciendo en dicho edificio hasta que fugados los indios sublevados se restableció la calma con la llegada de la policía de Santa Ana, mandada por el Sr. Juez.

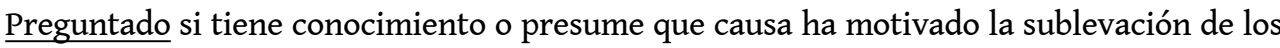
indios, dijo que no conoce, pero que presume que la causa ha de ser la falta de ciertos alimentos i sobre todo el hacer trabajar las mujeres, según manifestó al

\section{Folio 24 reverso}

declarante el mismo Melideo.

Preguntado en qué consiste los robos perpetrados por los indios dijo: Que no sabe nada al respecto.

Preguntandole si tiene conocimiento de que Melideo ó Yancamil mantuvieran relaciones íntimas i frecuentes con personas de fuera del establecimiento, dijo: que no.

Con lo que se terminó la presente declaración i leída que le fue al declarante se afirmó i ratificó en su contenido firmando con los testigos por ante mi de que certifico.

José A. Mujica

Juez de Paz

Patricio Salas

Testigo Manoel A. de Oliveira

Testigo Reginaldo I. Krieger

Acto continuo compareció ante mi i testigos con

\section{Folio 25}

quienes actúo, Don Francisco Estrada, llamado á declarar en esta causa quien previo juramento de ley que prestó en forma, fue examinado al tenor de las siguientes preguntas.

Preguntado por su edad, estado, profesion y domicilio, dijo: Que tiene veinte i cinco años de edad, de estado casado, i empleado en el Ingenio Azucarero del señor General D. Rudecindo Roca donde tiene su domicilio.

Preguntado si tiene conocimiento de la sublevación y fuga de los indios Pampas que trabajaban en el citado establecimiento del citado señor General Roca, el día veinte i tres del corriente, como se produjo el hecho, cuándo y de que manera dijo: que como á la una de la tarde del mencionado día hallandose 


\section{Folio 25 reverso}

el declarante trabajando en la Fábrica, cuando sintiendo gran griteria salió fuera de la misma encontrándose con un grupo de peones que con el Señor Jordan a la cabeza llegaban del depósito de la locomotora. Que entonces el declarante se apoderó de una carabina, que no recuerda de manos de quién la tomó, é hizo un disparo a uno de los indios que venían a la cabeza del grupo de indios armados que conducía pricionero al capataz Cirilo Ríos. Que enseguida el declarante quizo repetir los disparos negandosele la carabina á dar fuego. Que acto continuo el declarante reunió el grupo de indios matacos que están bajo sus ordenes i desarmándolos de los machetes que tenían entrególos a los cristianos, i reuniendo a los mencionados

\section{Folio 26}

indios matacos que asustados trataban de disparar, los condujo el declarante al cañaveral donde permaneció con ellos hasta que terminado el tumulto volvió con los mismos al trabajo.

Preguntado en qué consisten los robos perpetrados por los indios dijo: Que no, pues como deja dicho se ausentó con los matacos al cañaveral.

Preguntado si tiene conocimiento o presume que causa ha motivado la sublevación de los indios, dijo: que no.

Preguntado si tiene conocimiento de que Melideo i Yancamil mantuvieran relaciones íntimas i frecuentes con personas de fuera del establecimiento, dijo: que no.

Con lo que terminó la presente declaración que leída que le fue al declarante se afirmó i

\section{Folio 26 reverso}

ratificó en su contenido i firmó con los testigos por ante mi de que certifico $=($ tachado $)=$ la presente declaración $=$ No vale .

José A. Mujica

\section{Francisco Estrada}

Testigo Manoel A. de Oliveira

Testigo Reginaldo I. Krieger

En veinte i siete del mismo compareció ante mi i testigos con quienes actúo D. Arturo Kirschner, testigo llamado á declarar en esta causa, quien previo juramento de ley que prestó en forma, fue examinado al tenor de las siguientes preguntas.

251 Preguntado por su edad, estado, profesion y domicilio, dijo: Que tiene cuarenta i 


\section{Folio 27}

\section{Folio 28}

siete años de edad, de estado soltero, de profesión agrimensor empleado en el Establecimiento del Señor General Roca donde tiene su domicilio.

Preguntado si tiene conocimiento de la sublevación i fuga de los indios Pampas que trabajaban en el Establecimiento del citado señor General Roca el día veinte i tres del corriente, como se produjo el hecho, cuándo y de que manera dijo: que como a la una de la tarde del día veinte i tres hallábase el declarante en la casa que ocupa junto á la estacion de la locomotora cuando sintiendo gran ruido salió fuera encontrándose con un numeroso grupo de indios que venían armados con palos, machetes, hondas, boleadoras $\mathrm{i}$ lanzas, lo que visto por el declarante se encerró en su habitación, observando desde otra

\section{Folio 27 reverso}

puerta que está detrás de la casa lo que hacían los indios, i habiendo salido un momento despues recibió un golpe en la mano sin saber quien se la había dado, por lo que el declarante se encerró nuevamente en su habitación, donde permaneció largo tiempo, transcurrido el cual i no sintiendo mas ruido volvio a salir i no viendo mas indios sacó el fuego de la locomotora é inmediatamente dirigiendose al cuarto de la bomba hizo lo mismo con el fuego de esta dirigiendose enseguida a la Fabrica. Que despues de un rato salió de esta con algunas personas mas i habiéndose ya ido los indios se dirigió nuevamente al cuarto de la bomba donde vió con estrañeza que se hallaba encendido el fuego, sin saber quien pudo haberlo hecho por cuanto el declarante

como deja dicho, lo habia sacado momentos antes. Que en esta ocasión pudo presenciar el cuadro de destrozos causados por los indios en la poblacion ocupada por Jordan cuya puerta se encontraba rota, en la poblacion ocupada por el negocio de donde se habian llevado cuantos articulos de tienda habia, i en las poblaciones que comúnmente ocupa el Señor General Roca i el cocinero Esteban Daneri con su familia, cuyas puertas se encontraban también abiertas y con señales de haber sido forzadas. Que en esa circunstancia el declarante á vista de varias personas cerró como le fue posible las puertas del negocio, sin permitir que nadie tocara nada, guardando la llave en su poder hasta el dia siguiente en que hizo entrega de ella

\section{Folio 28 reverso}

6 al encargado del mismo Don Guillermo Almeida, en presencia del mayordomo del establecimiento D. Jordan Hummel.

Preguntado si tiene conocimiento o presume que causa ha motivado la sublevación de los indios, dijo. Que positivamente no las conoce, pero que presume que sea por haberlas puesto á trabajar á las mujeres de estos, pues que por lo que respecta a la alimentación 
diaria que se le daba no podía ser mejor ni más abundante, según ha visto el declarante en distintas ocasiones que por curiosidad se ha acercado al rancho de los indios.

Con lo que se dio por terminada la presente declaración que leída que le fue al declarante se afirmó i ratificó en su contenido

\section{Folio 29} conocimiento del señor Juez, en prevision de los que pudiera suceder, la declarante se asomó á la puerta de la casa que en dicho Establecimiento ocupa atraida por la curiosidad de saber adonde se dirigia corriendo el señor Jordan, cuando en estos momentos vé la declarante que de los galpones ocupados por los indios pampas salian todos estos en grupo numeroso i armados de palos, cuchillos i machetes, dando espantosos gritos dirigiendose a las poblaciones ocupadas por el negocio i el mayordomo Señor Jordan. Que llegado dicho grupo de indios á la casa de Jordan donde se encontraba la mujer de éste con sus hijos i el peon Gabriel Florentin, con el caballo ensillado, entra- 


\section{Folio 30 reverso}

-ron á la casa de donde sacaron preso a dicho peón. Que en estos momentos se acercó a la declarante el indio Juan Rosa i le dijo "que se escondiera inmediatamente con sus hijos por que los indios sublevados la iban a matar". Que acto continuo i sin perdida de tiempo la declarante con sus tres hijos i acompañada de la mujer é hijos de Ignacio Flores, llamada Josefa Villaloa se encerró en las piezas del Señor General Roca. Que estando allí como al cuarto de hora se acercó un grupo de indios los que empezaron a dar fuertes golpes a las puertas i ventanas, pidiendo á gritos que se les abriera, á lo que tuvo que acceder la declarante. Que una vez abiertas las puertas entraron todos los indios con Yancamil á la cabeza pidiendole á la

\section{Folo 31}

declarante que les entregara las balas que ellos sabian que había en el altillo, asegurándole Yancamil á la declarante, que á ella personalmente no le sucedería nada, porque no era á ella sino a Jordan i a Esteban a los que querían encontrar. Que inmediatamente los referidos indios empezaron á apoderarse de la ropa i objetos que encontraban á mano, mientras Yancamil con su machete levantaba la puerta del altillo por donde con amenazas de muerte hizo penetrar á un hijo de la declarante llamado Anselmo, de ocho años de edad, con el fin de que le alcanzara todas las balas que habia. Que en estos momentos arrojada la declarante al patio, a empujones con un hijo en los brazos, por el mismo Yancamil, se encontró allí con la mujer e hijos de Jordan

\section{Folio 31 reverso}

que también llevaban prisionera, asi como con el peon de la bomba llamado Ignacio Borja á quien le tenian atados los brazos por atrás de la espalda. Que enseguida determinado por los indios el registro i saqueo de las habitaciones en que la declarante se habia refugiado con sus hijos, estos emprendieron la marcha por la costa en dirección a un monte espeso que hay como á veinte cuadras abajo del establecimiento, donde por primera vez hicieron alto, llevando prisionera a la declarante i su dicho hijo menor asi como a las demás personas que en igual carácter iban i que ha mencionado ya, que llegados á este monte la declarante pudo observar á pesar de estar separada i con centinela, que los indios que tenían armas fueron colocados por Yancamil en varios puestos á manera de cen-

\section{Folio 32}

-tinelas, mientras la canoa embarcaba indios para pasarlos al frente, a la costa paraguaya donde se alcanzaban á ver los vaporsitos "Huascar" i "Fenix" con la mayor parte de la indiada. Que en cuanto terminaba de esta manera el embarque de los indios que la canoa podía llevar, i esta se separaba de la costa, los que quedaban á este lado, siempre con Yancamil a la cabeza como gefe, emprendían de nuevo la marcha por la misma costa hasta dar tiempo á que regresara dicha canoa, llevando como es consiguiente á la declarante i 
demás prisioneros. Que de esta manera han hecho los indios tres paradas, observando en todas ellas las mismas precausiones, hasta que á las nueve de la noche proximamente pasaron los últimos en cuatro ó

\section{Folio 32 reverso}

cinco viages que hizo la canoa en esta tercera i última parada, que fue cuando la dejaron en libertad á la declarante i demás compañeros de prision. Que en la segunda parada de los indios que la llevaban presa á la declarante, i como á eso de las tres ó tres i media de la tarde llegó á poca distancia de donde estos se encontraban el Sarjento de Policia del Distrito Don Nemecio Cepeda acompañado de dos soldados mas de dicha Policia, á quienes inmediatamente de ver ordenó Yancamil a los suyos que se le hiciera fuego siendo él el primero en hacerlo, el que fue contestado por Cepeda y los suyos. Que de resultas de esto murió en el acto de un balazo un indio de los sublevados y que hacía fuego, llamado Lincon, siendo también herido de bala el maquinista

\section{Folio 33}

del Huascar Teófilo López, que iba acompañando al Sarjento Cepeda. Que acto continuo vió la declarante que Cepeda i los soldados que los acompañaban se retiraban de alli en direcion al monte, llegando un instante después el indio Juan Rosa, que dijo a Yancamil que el Juez de Paz de Santa Ana reunía gente con el fin de atacarlo.

Preguntada si tiene conocimiento o presume que causa ha motivado la sublevación de los indios, dijo: que no.

Con lo que se terminó la presente declaración y leída que le fue a la declarante se afirmó i ratificó en su contenido firmando con los testigos por ante mi de que certifico $=$ entre renglones $=$ donde por primera vez hi-

\section{Folio 33 reverso}




\section{Folio 34}

\section{Folio 35} compañeros de prisión. indios, dijo: que no. conde que certifico.

José A. Mujica

Juez de Paz

Roca donde tiene su domicilio.

Preguntado si tiene conocimiento de la sublevación y fuga de los indios Pampas que trabajaban en el establecimiento Azucarero del precitado General Roca, como se produjo el hecho, cuándo y de que manera dijo. Que el día veinte i tres del corriente como á la una de la tarde hallándose el declarante en el cuarto de la bomba donde trabaja, oyó de pronto un tiro, i habiendo salido a la puerta á ver qué ocurría se encontró con un grupo de indios armados los que iban capitaneados porYancamil, quien ayudado por otro indio le ató las manos atrás de la espalda al declarante. Que acto continuo condujeron á este como asi mismo a la mujer de Jordan con sus

\section{Folio 34 reverso}

hijos, que ya traian con ellos en dirección á la pieza que acostumbra habitar el señor General Roca, en la cual vió penetrar a los indios capitaneados siempre por Yancamil, quien de allí á unos instantes salió con la mujer de Esteban i un hijo, como asi mismo otra mujer, poniéndose inmediatamente en marcha el grupo de indios siguiendo la costa, con Yancamil al frente i llevando prisioneros á las personas mencionadas en unión con el declarante, caminando como unas veinte cuadras en las que hicieron alto para dar lugar á embarcarse en la canoa unos indios para pasar al otro lado siguiendo despues la marcha. Que saliendo de allí a un rato hecho nuevamente alto, los indios oyó

el declarante dos descargas sin que pudiera ver que era lo que sucedía, pues se hallaba echado en el suelo i rodeado de indios armados que enseguida se pusieron nuevamente en marcha, llevando al declarante i demás prisioneros, los indios hasta un parage de la costa donde se embarcaron los últimos indios que quedaban en la canoa, y desatando previamente al declarante le dijeron que estaba en libertad como igualmente sus

Preguntado si tiene conocimiento o presume que causa ha motivado la sublevación de los

Con lo que terminó la presente i leída que le fue al declarante se afirmó i ratificó en su

\section{Folio 35 reverso}

-tenido, firmando a su ruego por decir no saber Don Joaquin Duarte, por ante mi i testigos

Amigo de Ignacio Borja por no saber firmar 

declarante mandó en busca de Jordan por una parte, mientras Centeno lo buscaba por otra. Que encontrado i avisado Jordan de este hecho, poco despues del toque de campana para que los peones vinieran á almorzar, este se dirigio apresuradamente a la fábrica acompañado de Centeno, con el fin de reunir algunos peones i preparar la defensa. Que un momento despues de haber salido Jordan en direccion á la fábrica se presentó en la casa que la declarante ocupa un numeroso grupo de indios encabezados por Yancamil i armados de machetes, palos $\mathrm{i}$ hachas pidiendole a gritos $\mathrm{i}$ con amenazas a la dclarante que les entregara las balas que habia allí, entran-

\section{Folio 37}

-do todos los indios al interior de la casa. Que entonces la declarante bajo el imperio del terror que estos indios le habian infundido les abrió uno por uno todos los baules i cajones que habia allí para que vieran que no habia balas, siendo víctima enseguida de los mayores ultrages despues de haber escapado milagrosamente de ser asesinada juntamente con un hijo que tenía en los brazos, por uno de los indios sublevados que por dos veces le tiró unos hachazos que la declarante pudo evitar desviando su cuerpo. Que de allí los indios la sacaron á empujones yla llevaron con sus dos hijos al cuarto de la bomba, desde donde presenció cuando los otros que allí habían quedado, siempre con Yancamil á la cabeza, sacaban i se distribuían los remington, machetes i alguna 


\section{Folio 37 reverso}

ropa de uso de la declarante como así mismo siete pesos moneda nacional que tenía en uno de los cajones de la mesa; que desde al cuarto de la bomba la declarante presenció el saqueo de la casa de negocio i el embarque en la canoa i vaporcitos Huascar i Fenix de una parte de los indios i de todas las mujeres i criaturas de estos. Que como media hora ó tres cuartos de hora después de encontrarse presa la declarante en el cuarto de la bomba, i después de haber zarpado aguas abajo los dichos vaporcitos el grueso de los indios que quedaba en tierra emprendió la marcha por la costa llevandola á la declarante i sus hijos, asi como al peon Ignacio Borja que también habia sido constituido en prisionero. Que al pasar los referidos indios por delante de la casa

\section{Folio 38}

que habita en el establecimiento el Señor General Roca, empezaron los indios á empujar las puertas con sus remingtons, a fin de que las personas que había adentro les abrieran. Que abiertas estas por Juana la mujer de Esteban que estaba alli entraron la mayor parte de los indios pidiéndole a Juana con gritos $i$ amenazas que les entregara las balas que habia en el altillo. Que acto continuo el mismo Yancamil la sacó a Juana dejandola con la declarante, regresando este adonde estaban sus compañeros. Que concluido el registro i saqueo de dichas habitaciones los sublevados siguieron la marcha siempre por la costa $\mathrm{i}$ en direccion á un monte que está como a veinte cuadras del establecimiento donde hicieron la primera parada. Que en esta primera parada, se embarcaron como veinte indios en la

\section{Folio 38 reverso}

canoa que momentos antes había llegado vacía de la costa paraguaya donde se avistaban los vaporcitos Huascar i Fénix. Que separada la canoa á alguna distancia de la costa con los indios que había embarcado, para pasar a la costa paraguaya, Yancamil con los indios i prisioneros que llevaba, i entre los que iba la declarante, se puso en marcha siempre por la misma costa hasta llegar á otro monte más espeso i enmarañado que dista como diez cuadras del primero, donde por segunda vez volvieron á hacer alto, que en esta segunda parada se volvieron a embarcar en la canoa que ya volvía vacía, como otros veinte i tantos indios. Que pocos momentos despues de que los indios hicieron alto en esta segunda parada despues que la canoa se retiraba con los que habia embarcado, llegó el Sargento

\section{Folio 39}

de Policía del Distrito Don Nemecio Cepeda acompañado de los soldados de la misma Policia y algunos particulares, en su mayor parte peones del establecimiento. Que inmediatamente que Yancamil distinguió al Sargento Cepeda por entre los árboles como a los que le acompañaban ordenó a los indios que se hallaban armados de remington i que serían proximadamente ocho, que hicieran fuego, siendo él el primero en hacer fuego. Que como consecuencia de esto, la declarante vio caer muerto de un balaso a uno de los 
indios que hacía fuego llamado Lincon, habiendo llegado a su conocimiento despues, que en el mismo encuentro habia sido herido el foguista Teófilo López que acompañaba a Cepeda. Que despues de esto i cuando yá Cepeda i su gente se habia retirado, los indios empren-

\section{Folio 39 reverso}

-dieron nuevamente su marcha sin separarse de la costa hasta una distancia como de quince cuadras mas ó menos, donde hicieron alto por tercera y última vez, ya mui cerca de la oracion. Que en esta tercer parada la canoa hizo varios viages hasta pasar á todos los indios á la costa paraguaya adonde aun se encontraban i alcanzabanse a ver los vaporcitos. Que en el último viage de la canoa la declarante i demas personas que con ella estaban en calidad de presos, fueron puestas en libertad por los indios que en ella debían embarcarse emprendiendo á las mismas horas nueve de la noche, el viage de regreso al establecimiento.

Preguntada si tiene conocimiento o presume que causa ha motivado la sublevación de los indios pam-

\section{Folio 40}

-pas: dijo: que no.

Con lo que se dio por terminada la presente declaración i leída que le fue a la declarante se afirmó i ratificó en su contenido firmando a su ruego por decir no saber D. Agustin Ossola por ante mi i testigos de que certifico. Entre líneas = previniéndole este mismo = que $=$ Cepeda por entre los árboles $=$ Vale $=$ Tachado $=l o=$ no vale .

José A. Mujica

314 Juez de Paz

315 Amigo de Secundina Achiar

316 Por no saber firmar

317 Agustin Ossola

Testigo Manoel A. de Oliveira

Testigo Reginaldo I. Krieger

En treinta del mismo compareció ante mi i testigos con quienes actúo Cirilo

\section{Folio 40 reverso}

Ríos, quien previo juramento de ley que prestó en forma, fue examinado al tenor de las siguientes preguntas.

Preguntado por su edad, estado, profesion y domicilio, dijo: Que tiene veinte i tres años de edad, de estado soltero, y es capataz en el establecimiento azucarero del Señor General Don Rudecindo Roca donde tiene su domicilio.

Preguntado si tiene conocimiento de la sublevación y fuga de los indios Pampas que trabajaban en el establecimiento del citado General Roca, ocurrida el día veinte i tres del 
corriente, como se produjo el hecho, cuándo y de que manera dijo: que el mencionado día veinte i tres poco antes de la una de la tarde hallabase el declarante en su casa, cuando llegó a la misma el mayor-

\section{Folio 41}

-domo Señor Jordan acompañado de Yancamil, i llamando el primero aparte al declarante le pidió le entregara, sin que Yancamil viera, los cartuchos á bala que tuviera. Que entonces el declarante de cinco cartuchos que tenía, le entregó por abajo del poncho al Señor Jordan, tres, reservándose el declarante dos de estos que guardó en un bolsillo de su pantalon. Que al irse Jordan de casa del declarante le dijo "estese pronto Rios" sin que este pudiera comprender qué significaban dichas palabras. Que inmediatamente el declarante salió de su casa en direccion á la fábrica para ir a su trabajo, cuando al llegar a esta encontró a Jordan con otro capataz, incorporandose el declarante á los mismos i marchando los tres en direccion al cañave-

\section{Folio 41 reverso}

-ral. Que momentos despues i hallandose a una distancia de una cuadra de la Fábrica, Jordan se separó del grupo i volvió en dirección a ésta, i algunos instantes después sintió el declarante que este ultimo lo llamaba por repetidas veces diciéndole "venga Ríos". Que acto continuo el declarante se dio vuelta i oyó una gran gritería producida por los indios, distinguiendo al mismo tiempo un numeroso grupo de estos en la puerta de su casa encabesados por Yancamil, quien en aquellos momentos ataba con una soga á la mujer del declarante. Que entonces este acercándose a los indios i dirigiéndose a Yancamil le dijo que no matara á su mujer, que lo matara a él. Que entonces Yancamil largando a la mujer del declarante agarró a este por

\section{Folio 42}

ambas muñecas i acompañado de los demás indios lo condujo en direccion al embarcadero. Que en aquellos momentos Jordan que se hallaba en la Fábrica hizo un disparo de remington á Yancamil gritándole al mismo tiempo que "soltára a Rios" á lo que Yancamil le contestó "que á él (Jordan) tambien quería agarrar". Que acto continuo embarcaron al declarante en el vaporcito "Huáscar" en el cual había embarcados mujeres indias i criaturas e inmediatamente Melideo, que era el que mandaba, dio orden de ponerse en marcha, dirigiendose el vapor impulsado por la corriente, pues la máquina no funcionaba, aguas abajo, arribando media hora después a la costa paraguaya donde tocaron tierra poniéndose inmediatamente en marcha i

\section{Folio 42 reverso}

caminando como hasta las dos de la mañana hora en que hicieron alto en el monte, continuando el declarante con los brazos atados detrás de la espalda, cuya operación hizo con él el indio Simon el día anterior en los momentos en que era embarcado i cuya operación presencio la mujer de Jordan desde su casa. Que tres días despues consiguió 
escaparse el declarante, asi como su compañero Gabriel Florentino amparados por los montes en que habian hecho alto los indios que lo llevaban, dirigiéndose á la Villa Encarnación adonde llegó el mismo día como á eso de las tres de la tarde pasando al día siguiente á Posadas, de donde anoche á regresado nuevamente al Establecimiento. Que al regresar el declarante, anoche, al es-

\section{Folio 43}

tablecimiento, hablando con Centeno de la sublevacion este le dijo, que antes de que ella ocurriera le avisó con tiempo a Jordan de que ella iba a producirse, pero que este en vez de dar crédito á sus palabras los recibió de muy mal modo i echó a pasear con palabras hirientes e indecorosas.

Preguntado si tiene conocimiento o presume que causa ha motivado la sublevación de los indios, dijo: Que no.

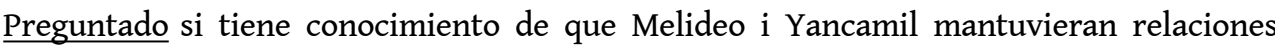
íntimas i frecuentes con personas de fuera del establecimiento, dijo: que no.

Con lo que se dio por terminada la presente declaración i leída que le fue al declarante se afirmó i ratificó en su contenido

\section{Folio 43 reverso}


madrugada del mismo día habían fugado del citado establecimiento del Señor General Roca, siendo proximadamente como la una i media ó dos de la tarde se encontró a pocas cuadras

\section{Folio 44 reverso}

del Establecimiento del Señor Puck, con el sordo Juan Garcia i el ingeniero mecánico D. Guillermo Gouchard á quien llevaba en ancas de su caballo, los que le avisaron al declarante que todos los indios del establecimiento se habían sublevado, i que en aquellos momentos estaban saqueando i asesinando; siendo esta la causa de que ellos se fueran. Que entonces el declarante con los dos soldados de Policia que llevaba llamados Tiburcio Collado i Fortunato Garcia se vino á media rienda al mencionado Establecimiento con el fin de prestar su auxilio, llegando a él, momentos después de que los indios se habían ido, los unos por agua, embarcados en la canoa i vaporcitos "Huáscar" y "Fénix", llevando prisioneros a Cirilo Rios i Gabriel Florentino, i los otros por tierra, en direc-

\section{Folio 45}

-cion al monte que está sobre la costa, distante veinte cuadras abajo del Establecimiento, llevándose prisioneras á la mujer é hijos de D. Jordan Hummel, á la mujer i un hijo del cocinero Esteban Daneri, así como al peón de la bomba llamado Ignacio Borja. Que á su llegada i en los pocos momentos que el declarante permaneció en el establecimiento, fue informado por distintas personas de que este grupo de indios, el mas numeroso, iba armado de remingtons, machetes, lanzas i boleadoras llevando como gefe á Yancamil. Que acto continuo i sin perdida de tiempo, el declarante, en cumplimiento de sus deberes, se puso en su seguimiento con los dos soldados que lo acompañaban, con el propósito de ver si de alguna manera se podía salvar á

\section{Folio 45 reverso}

las personas que los indios sublevados llevaban presas, si es que estas no habian sido asesinadas. Que llegado al lugar donde los indios estaban i como á cuarenta varas de ellos, el declarante vió que la canoa se atracaba a la costa saliendo cargada unos momentos despues con indios, en direccion a la costa paraguaya. Que momentos despues de su llegada a este lugar i en circunstancias que el declarante con sus soldados operaba un cambio con el fin de aproximarse más a los indios, que hasta entonces no lo habían sentido, se encontró con varias personas que venian en su auxilio mandadas por el infrascrito, que ya se encontraba en el Establecimiento, los que, asi como el declarante i sus soldados fueron sentidos i vistos por

\section{Folio 46}

los indios que Yancamil habia puesto de guardia. Que acto continuo de ser sentidos por los indios, estos se reunieron en número como de ocho todos ellos armados con remington i con Yancamil á la cabeza, empezando hacerles un fuego nutrido al que el declarante se vio obligado forzosamente a contestar. Que en esta situación, habiendoseles 
descompuesto las carabinas que llevaban Garcia i Collado, i en la imposibilidad material de poder conseguir el rescate de los prisioneros por cuanto habia quedado casi solo, ordenó la retirada. Que en este momento fué herido de bala el foguista del vapor "Huáscar" llamado Teófilo López, que momentos antes se habia reunido al declarante, asi como también vio caer muerto a uno

\section{Folio 46 reverso}

de los indios sublevados i que les hacia fuego, llamado Lincon. Que de regreso al establecimiento, donde el infrascrito se hallaba le dio cuenta de los sucedido i que es cuanto deja manifestado.

Con lo que se dio por terminada la presente declaración i leída que le fue al declarante se afirmó i ratificó en su contenido firmando a su ruego por decir no saber D. José S. Marquez por ante mi i testigos de que certifico. billete del Banco Paraguayo de quince reales, que el declarante se negó a recibir. Que entonces la citada india pampa abonó el gasto con dos billetes del precitado banco, uno de cinco reales i otro de dos que fueron recibidos por el compareciente. Que posteriormente se presentó en el negocio del declarante un indio pampa de regular altura i como de veinte i cinco á treinta años de edad quien manifestó al declarante ser maquinista ó foguista, dándose más el primero de estos títulos, del vaporcito Huascar, el cual tenía un paquete de billetes del Banco Paraguayo en la mano, de los que exhibió uno de quince reales 


\section{Folio 48}

al compareciente afin de que se cobrara el gasto que habia hecho, consistente en cinco reales, cuyo billete no habiéndolo querido recibir el declarante, le fue entregado entonces por el citado indio uno de cinco reales también del Banco paraguayo el que fue recibido por el compareciente.

Con lo que se terminó la presente declaración i leída que le fue al declarante se afirmó i ratificó en su contenido firmando con los testigos por ante mi de que certifico.

José A. Mujica

Juez de Paz

Salvador Lentini

Testigo Manoel A. de Oliveira

Testigo Reginaldo I. Krieger

Acto continuo compareció ante mi i testigos con quienes actúo D. Vicente Baez, llamado á declarar en

\section{Folio 48 reverso}

esta causa quien previo juramento de ley que prestó en forma, fue examinado al tenor de las siguientes preguntas.

7 Preguntado por su edad, estado, profesion y domicilio, dijo: Que tiene veinte i cuatro años de edad, de estado soltero, i es dependiente de la casa de negocio que los señores Calvo Hermanos tienen en esta localidad donde tiene su domicilio.

Preguntado de si tiene conocimiento de que hace poco tiempo ha llegado á la casa de negocio donde se halla uno de los indios pampas sublevados en el establecimiento azucarero del señor General Roca, á proveerse de algunos artículos pagando con billetes del Banco paraguayo, dijo: que hará como mes i medio llegó a la citada casa de negocio donde el declarante se encuentra un indio pampa de estatura mas bien baja que alta, $\mathrm{i}$ como de treinta años de edad, el que habiendo comprado algunos artículos, entregó al declarante pa-

\section{Folio 49}

-ra que se cobrara el importe de los mismos un billete de veinte pesos del Banco paraguayo, i negándose el declarante a recibirlo, se marchó el citado indio.

Con lo que se terminó la presente declaración i leída que le fue al declarante se afirmó i ratificó en su contenido firmando con los testigos por ante mi de que certifico.

José A. Mujica

Juez de Paz

Juan V. Baez

Testigo Manoel A. de Oliveira 
Testigo Reginaldo I. Krieger

Santa Ana Junio 30 de 1888

Por terminada, elévese.

José A. Mujica

Juez de Paz

Posadas, Julio 4 de 1888

Elévese al Señor Juez Na-

\section{Folio 49 reverso}

-cional del Territorio, á los efectos que pudiere haber lugar, con la nota acordada.

J. Reyes

Emilio Baliño

Sect. Int.

\section{Folio 50}

Posadas, Julio 4 de 1888

Al Señor Juez de Paz del Territorio,

Dr. Don Darío Quiroga

Tengo el honor de adjuntar á V.S. el sumario instruido por el Juez de Paz del distrito de Santa Ana, con motivo de la sublevación y fuga de varios indios papas del ingenio "San Juan" ocurrida el 23 de Junio ppdo., á los efectos del decreto del Señor Gobernador interino del Territorio, recaído en el mismo.

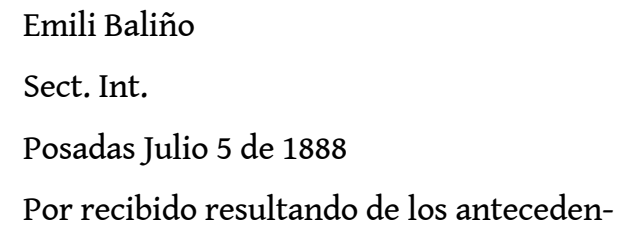

\section{Folio 50 reverso}

-tes acompañados suficientes indicios para creer en la existencia de los delitos de asalto y huida y responsables de ellos como autores y Gefes de un complot los indios pampas Melideo y Yancamil, decrétase su detención á cuyo fin se solicitará a las autoridades paraguayas su extradición por intermedio de la legación argentina, habiendo además recomendado su captura a las autoridades policiales del territorio (...) que sean habituales.

Quiroga.

Ante mí: Augusto Blanco

Escri. Secre. 


\section{Folio 51}

Juez- Habiendo encontrado el auto precedente sin autorizarse por mi antecesor, lo he autorizado y lo participo a Ud. a los efectos que hubiere lugar.

\section{Oficina Febrero 25 de 1890}

Augusto Blanco

Escri. Secre.

Febrero 25

En vista de lo manifestado en la precedente nota del decreto, ir formalizando las diligencias ordenadas.

Quiroga.

Ante mí:

Augusto Blanco

Escri. Secre.

El veinte i seis se liberaron los exhortos y oficios ordenados -conste.

Blanco

\section{NOTES}

1. Parte del análisis del documento que se presenta en este artículo fue incluido en "De la Frontera Sur a Tucumán y Misiones: Itinerarios de los prisioneros hacia los ingenios azucareros", un capítulo -en coautoría con Jorge Sosa- del libro En el país de nomeacuerdo. Archivos y memorias del genocidio del estado argentino sobre los pueblos originarios (1870-1950), compilado por Walter Delrio, Diego Escolar, Diana Lenton y otros (Ed. Universidad Nacional de Río Negro, en prensa al momento de la escritura de este artículo).

2. Si bien la política de reparto de indígenas cautivos se remonta a tiempos coloniales (Pérez Zavala 2012, p. 4), la misma se intensificó a partir de la década de 1870, cuando confluyen la intensificación del conflicto fronterizo, especialmente en la Pampa central-Patagonia norte, con el auge de las agroindustrias en el norte del país, y especialmente la industria azucarera.

3. Hermano del entonces ministro de Guerra Gral. Julio A. Roca; hacia el final de su vida recibió el ascenso al grado de general. Fue gobernador del Territorio Nacional de Misiones entre 1882 y 1891 y falleció en 1903.

4. En otro lugar (Lenton y Sosa 2016) observamos que los principales caciques suelen constituir la excepción en estos itinerarios, probablemente porque la figura de prisionero político prime en ellos por sobre la de trabajador-prisionero. Por ejemplo, Melideo, tío de Yancamil, fue apresado por Rudecindo Roca en noviembre de 1878 (Depetris 1992), y no tenemos noticias de su envío a Tucumán sino a Martín García y luego a Santa Ana, Misiones.

5. “(...) el Comandante Roca ha hecho fusilar a sesenta indios ranqueles. Tal aseveración es por demás grave, es un crimen de lesa humanidad; es un bofetón á la civilización, (...)” (La Nación, 16 de noviembre de 1878). Ver mayor desarrollo en Depetris 2002, Alcaraz 2008, Lenton y Sosa 2016. 
6. José Gregorio Yancamil, nieto de Painé Guor y sobrino de Panguitruz Guor (Mariano Rosas) y Epumer (Epugner), nació en 1850 en Leuvucó y falleció en Emilio Mitre en 1933 (Depetris y Vigne 2000; Abbona 2013). Aunque algunos autores (por ejemplo, Hux 1991) prefieren la ortografía Llancamil, siguiendo a algunas fuentes, prefiero utilizar la versión Yancamil dado que es tal como aparece en el documento de 1888 .

7. Como reflexiona Depetris (1992), lo acontecido en Villa Mercedes no difería de lo que estaba ocurriendo en Junín, Bragado, Trenque Lauquen, Azul, Bahía Blanca, donde se concentraban y derivaban caravanas hacia Buenos Aires, Rosario, Martín García y Tucumán. Y así, pampas, salineros, catrieleros, ranqueles y otros, "mezclados, iniciaban el camino del destierro". Como ya hemos señalado en otro lugar (Lenton 2005), el destino final de las familias o individuos en sus lugares de trabajo, o en casas de familia, no registra esta diversidad de origen. Aun cuando, como documentan Mariano Nagy y Alexis Papazian (2016), las listas de ingreso a Martin García consignan a los diferentes individuos en sus diversas identidades territoriales, a los ingenios ingresan como "pampas" o simplemente "indios".

8. Gutiérrez et al. (2014) denuncian un origen fraudulento en la operación de compra de los terrenos sobre los que se asentó el ingenio San Juan, que llegaba a sumar el triple de superficie que la actual reserva privada San Juan. Además, los mismos autores describen la denuncia por defraudación al fisco que se hiciera contra Rudecindo Roca en abril de 1888, por la utilización de materiales de construcción y trabajadores de la gobernación en su propiedad particular (Gutiérrez et al. 2010, p. 12). Más detalles sobre esta denuncia y sus casi nulas consecuencias en Guerra (1979).

9. M. Nagy y A. Papazian, com. pers.

10. Agradecemos a Pilar Pérez la indicación sobre este documento. Archivo General de la Nación, Expedientes Generales del Ministerio del Interior, año 1888, Legajo 11.

11. A pesar de esta última frase condenatoria, la defensa que el naturalista intenta para deslindar a su amigo Roca de las acusaciones por la dureza de la represión, exhibe el carácter en el que los trabajadores eran incorporados al ingenio, mientras contribuye a la naturalización del uso de los recursos del Estado para beneficio privado: "Si son cautivos, si son prisioneros de guerra, no puede suponerse que el general Roca, jefe disciplinario, haya confiado su custodia a guardianes puramente particulares sino a soldados de la Nación, que debían vigilarlos dentro de la propiedad privada. En este caso, son sus guardianes militares los que han hecho fuego sobre ellos, empleando el derecho de la guerra, de matar a los prisioneros fugitivos, crimen que ninguna ley condena. En ninguna parte consta que el Ministerio de la Guerra haya devuelto sus libertades a los Indios prisioneros, ni el General Roca ha hecho misterio de que iba a hacerlos trabajar en su ingenio". Y también: "Por lo menos en el caso actual, había sido una obra de caridad el sacarlos de la Isla Martín García, donde ciertos abusos cometidos por los empleados habían provocado gravísimas denuncias y un serio sumario, afirmándose que ello era una tumba de Indios" (Holmberg 1887).

12. Agradezco a Mariano Nagy y Alexis Papazian por compartir estos documentos. Ver: Nagy y Papazian 2016; Lenton y Sosa 2016.

13. Ver transcripción completa y fotografías en Anexo.

14. José Antonio Mujica era, además, administrador de la Colonia Santa Ana y defensor de menores en Posadas (Guerra 1979).

15. El sumario detalla 136 "de trabajo", 18 ancianos o inválidos, 59 mujeres y 49 "criaturas".

16. Agradecemos la información a la documentalista Ana Zanotti. La memoria de la sublevación reconvertida en "malón" transforma también la toma de las mujeres de los empleados como rehenes en el rapto de las mujeres del pueblo, "cautivas" esperables en un "malón pampa".

17. Cambas y Ferrier (1991) documentan otra revuelta de menores proporciones ocurrida en el ingenio San Juan en 1890. Poco después, R. Roca vendió el ingenio a una empresa de la familia Bemberg, que procedió a su desmantelamiento en 1895 (Guerra 1979; Gutiérrez et al. 2010, 2014). 
18. Anabela Abbona y José Depetris relevaron la documentación relativa al retorno de Yancamil a su tierra, para entonces parte del Territorio Nacional de La Pampa, junto a su esposa e hijos. A principios del siglo XX, luego de obtener un indulto presidencial, Yancamil se instaló definitivamente con su familia en Emilio Mitre, hasta su fallecimiento en 1933 (Depetris y Vigne 2000; Abbona 2013).

\section{ABSTRACTS}

This article retrieves and offers a critical reading of the file of the "Sumario levantado con motivo de la sublevación i fuga de los indios pampas que trabajaban en el establecimiento del Señor General Don Rudecindo [Roca]", dated June 24th, 1888, which was signed by José Mujica, judge of peace of Santa Ana (Misiones), and is catalogued in the General Archives of the Governorate of Posadas.

The so-called "Pampas' uprising", or "Pampas' malón", was an exceptional event in the context of the subjugation of Pampa and North-Patagonia peoples, the practice of dismembering and sharing out defeated groups by the state for the benefit of private owners, and the different possibilities of resistance to it. Several circumstances converged in this case so that the collective agency managed to overturn the constraints of the usually enormous disparity of physical, material and symbolic resources.

En este artículo se recupera y se ofrece una lectura crítica del expediente del "Sumario levantado con motivo de la sublevación i fuga de los indios pampas que trabajaban en el establecimiento del Señor General Don Rudecindo [Roca]", con fecha 24 de junio de 1888. El mismo, firmado por José Mujica, juez de paz de Santa Ana (Misiones), se encuentra en el Archivo General de la Gobernación de Posadas.

La llamada "sublevación de los pampas", o "malón de los pampas", constituyó un evento excepcional en el contexto del sometimiento de los pueblos pampeanos y norpatagónicos, la práctica del repartimiento de los grupos vencidos, por parte del Estado, para el beneficio de propietarios privados y las diferentes posibilidades de resistencia a la misma. Varias circunstancias confluyeron en este caso para que la agencia colectiva lograra derribar las constricciones de la usualmente enorme disparidad de recursos físicos, materiales y simbólicos.

\section{INDEX}

Keywords: Keywords:

Palabras claves: Palabras clave:

\section{AUTHOR}

\section{DIANA LENTON}

Universidad de Buenos Aires y CONICET, Argentina

dianalenton@gmail.com 